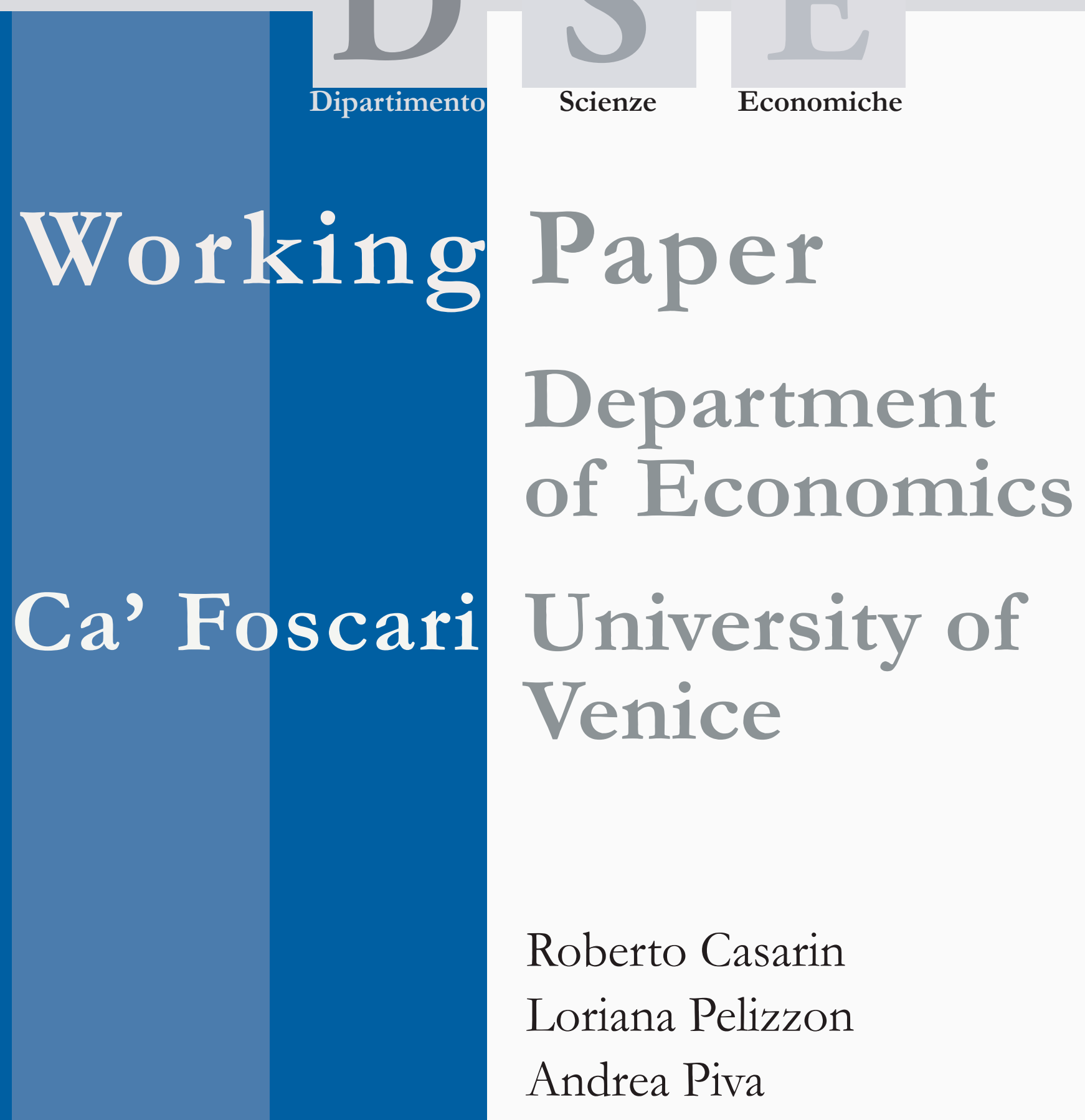

Italian equity funds: efficiency and perfomance persistence 


\title{
Italian Equity Funds: Efficiency and Performance Persistence
}

\author{
Roberto Casarin \\ University of Brescia \\ Loriana Pelizzon \\ University of Venice and SSAV, Scuola Studi Avanzati in Venezia
}

Andrea Piva

GRETA Associati

\begin{abstract}
Have Italian mutual funds been able to generate "extra-return”? Were some of them able to persistently beat the competitors? In this paper we address these questions and provide a detailed and systematic performance and return persistence analysis of the Italian equity mutual funds. We show that, in general, fund managers have not been able to score extraperformances and only few managers had stock picking ability or market timing ability. This evidence is consistent with the market efficiency hypothesis. Moreover, concerning performance persistence, first, we cannot trace out the hot-hand phenomenon on raw returns. The no persistence effect is fairly robust to: the performance measure, the temporal lag and the different methodology employed for testing persistence. Second, there has not been long-run persistence on risk-adjusted returns (we find a weak evidence of the reversal effect). Finally, the past performance displays weak evidence of the hot-hand effect on riskadjusted returns on four-month using cross-section tests. However, as soon as we analyse yearly intervals any evidence of persistence disappears.
\end{abstract}

\section{Keywords}

Mutual funds, Performance evaluation.

\section{JEL Codes}

G23, G21,G10, G12

\author{
Address for correspondence: \\ Loriana Pelizzon \\ Department of Economics \\ Ca' Foscari University of Venice \\ Cannaregio 873, Fondamenta S.Giobbe \\ 30121 Venezia - Italy \\ Phone: (++39) 0412349164 \\ Fax: (++39) 0412349176 \\ e-mail: loriana.pelizzon@unive.it
}

This Working Paper is published under the auspices of the Department of Economics of the Ca' Foscari University of Venice. Opinions expressed herein are those of the authors and not those of the Department. The Working Paper series is designed to divulge preliminary or incomplete work, circulated to favour discussion and comments. Citation of this paper should consider its provisional character.

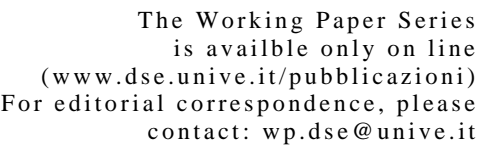

The Working Paper Series

is availble only on line (www.dse.unive.it/pubblicazioni) For editorial correspondence, please contact:wp.dse@unive.it

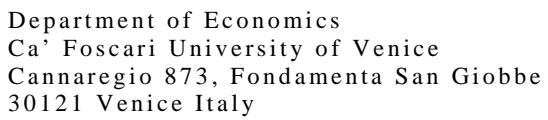




\section{INTRODUCTION}

Have Italian mutual funds been able to generate "extra-return"? Were some of them able to persistently beat the competitors? In this paper we address these questions and provide a detailed and systematic performance and return persistence analysis of the Italian equity mutual funds. The implications of this empirical work do not affect only the mutual funds market but also the entire Italian capital market and its efficiency.

The Italian managed fund industry has experienced a significant growth in recent years. The performance of these funds is an issue that has been well documented in the finance literature during the last two decades. Nevertheless, almost twenty years after the development of the Italian fund market, the investigation of the Italian fund performance is limited (see Cesari and Panetta (1998, 2002)), and a central issue, performance persistence of the Italian funds, has not been deeply examined yet. As far as we know, the only study on Italian fund performance persistence is conducted by Otten and Bams (2002). They investigate on the performance of 5 European countries mutual funds (included Italy) only investing in their domestic market. To perform their analysis they use only raw returns and time-series test of persistence. Our paper, however, focuses on a higher number of Italian mutual funds and a wider range of performance measures. Moreover, the presence of "superior abilities" is considered also in terms of ability to beat constantly the competitors and not only regarding the power to generate "extra-returns", for that reason a different approach called "cross-sectional tests" is used to analyse performance persistence that is based on three different tests, six performance measures and six different period lengths in order to assess the "long-run persistence" and the "hot-hand effect". As a consequence our analysis is complementary to that performed by Otten and Bams (2002) and allows us to provide a comprehensive analysis of fund performances that can provide interesting insights about the way the market has performed in this firstly phase of development. In addition, the implications of this empirical study could shed some light on the Italian capital market efficiency.

To reach our objectives, we explore two main topics and the relation between them: (i) the ability to generate extra-performances (in terms of "market timing" and "stock picking"); and (ii) the performance persistence analysis based on different lags, different measures of performance and several techniques.

Referring to the first objective, we estimate persistence employing the traditional Jensen's " $\alpha$ " (Jensen 1968, 1969) and the market timing coefficients (we use both the quadratic models of Treynor-Mazuy and Henriksson-Merton). All the analysis is performed using a six-factors model. In particular, we adopted the Chen, Roll and Ross's model (1986) plus the "market factor".

Moreover, we study the "hot-hand effect" and the "long-run persistence"; we analyse the phenomenon with (i) the Jensen's " $\alpha$ ", (ii) the total performance coefficients and (iii) the measures developed by Sharpe, Treynor and Sortino (in addition to raw returns). We evaluate the persistence of performance using different approaches. In the first approach (suggested by Brown et al. (1992)) persistence is evaluated using non-parametric tests based on two-way contingency tables, which analyse the performance of each fund relative to different stability classes of different length (e.g. divisions in octiles or in two macro-classes). The second approach is a multi-period persistence test proposed by Agarwal and Naik (2000). With this approach we carry out the performance persistence analysis with windows of three or four sub-periods (not only of two periods, as in "traditional" persistence tests). 
The analysis is based on the "theoretical framework" proposed by Cesari and Panetta (1998), for the performance evaluation part, and the international studies provided in the last ten years for the persistence study, with particular attention to the contributes of Hendriks, Patel and Zeckhauser (1993) and Agarwal and Naik (2000).

Our results suggest that Italian funds are not able to score extra-performances and, as a consequence, provide strong evidence in favour of the informationally efficient view of capital markets. Moreover, we find that the performance of Italian equity funds shows controversial results related to alternative methods (i) to estimate performance, (ii) to evaluate performance persistence and (iii) to determine the windows used to measure persistence.

The paper is organized as follows: in Section 1 we describe the sample of valuation; in Section 2 we estimate the risk adjusted performance measure; in Section 3 we present the methodology used to perform the persistence tests and we illustrate the results. Section 4 concludes.

\section{THE DATA SAMPLE}

We investigate the presence of "superior abilities" on a sample of funds (classified as "Azionari Italia" by Assogestioni ${ }^{1}$ at August 31 ${ }^{\text {st }}$ 1999) from March 1988 through August 1999, which invests $84 \%$ of the managed funds on Italian stocks. Data are extracted from the "Maneymate" database and crosschecked with information collected from the specialized press (in particular, from "Il Sole 24-ore"). In order to perform the analysis we required at least 36 months of data. Thus, the initial sample has been reduced from 76 to 57 elements. Figure 1 reports fund's distribution for months of activity.

\section{(Figure 1: Fund's distribution for months of activity)}

The data set contains monthly fund unit values (net values) of all the selected funds since their constitution and through changes in their name. The net fund unit value is determined after these costs are subtracted: (i) bank fees, i.e. the fees paid every year to the custodian bank as a percentage of the fund's NAV, (ii) management fees, i.e. the fees paid every year to the management company as a percentage of the fund's NAV, and (iii) trading costs, which include stamp duty, brokerage fees and bid-ask spreads paid by the funds on security transactions. Load fees however are not included because they are borne directly by the investors and do not influence the fund's NAV.

The sample does not present attrition rate, but it is affected, even though in a very limited way, by survivorship bias. In fact, even if the data set records changes in the name of mutual funds, the selection procedure does not include funds that changed investment policy, or that retired from activity. However, it seems rational to say that these operations affect the Italian market only marginally since these are typical operations of a market that presents high levels of competition (one of the main purposes of these operations is to hide bad performances from view of the public) and this is not the case of the Italian market in the past twenty years. 


\section{MUTUAL FUNDS ABILITY TO GENERATE EXTRA-PERFORMANCES}

\subsection{Models of performance measurement}

Two of the most used approaches to analyse fund performance are the Jensen's $\alpha$ and the market timing coefficient. In particular, Jensen's $\alpha$ is equal to the difference between the excess return (risk premium) on the fund and the theoretical excess return (expressed by the portfolio market proxy) that should have been earned by the portfolio, given its $\operatorname{risk}\left(\beta_{p M}\right)$.

$$
\alpha=\left(\bar{r}_{p}-\bar{r}_{f}\right)-\beta_{p M}\left(\bar{r}_{M}-\bar{r}_{f}\right)
$$

This measure, developed by Jensen $(1968,1969)$, requires some other specifications. In fact, it can be interpreted as the intercept of the following regression:

$$
r_{p t}-r_{f t}=\alpha_{p}+\beta_{p M}\left(r_{M t}-r_{f t}\right)+\varepsilon_{p t}
$$

where $E\left(\varepsilon_{p t}\right)=0$, and $V\left(\varepsilon_{p t}\right)=\sigma^{2}$

Extra-performances measured by Jensen's $\alpha$ could be analysed statistically using the intercept of OLS regression and performing statistical tests on the coefficient estimated in order to appreciate its significance. In general, a positive coefficient indicates superior abilities of the manager, whereas negative alphas indicate an insufficient performance to compensate the risk assumed.

To calculate $\alpha$-Jensen, the choice of the portfolio benchmark is a fundamental matter as it can affect the performance measure ${ }^{2}$. For this reason it is extremely important to choose efficient benchmarks in the mean-variance framework.

In general, the problem does not change if we assess that two or more risk factors influence simultaneously fund's returns. Indeed, a multifactor model is implemented in this work by the appliance of the following variant of the Chen, Roll and Ross's model $(1986)^{3}$ :

$$
\begin{aligned}
r_{p t}-r_{f t}= & \alpha_{p}+\beta_{1}\left(I P_{t}-r_{f t}\right)+\beta_{2}\left(U I_{k t}-r_{f t}\right)+\beta_{3}\left(V E I_{k t}-r_{f t}\right)+ \\
& \beta_{4}\left(R P_{k t}-r_{f t}\right)+\beta_{5}\left(T S S_{k t}-r_{f t}\right)+\beta_{6}\left(\text { Market }_{k t}-r_{f t}\right)+\varepsilon_{p t}
\end{aligned}
$$

where the risk factors are:

$$
\begin{aligned}
& \text { IP }=\text { Monthly variations of industrial production } \\
& \mathrm{UI}=\text { Unexpected inflation, defined as the difference between the expected (at the end } \\
& \text { of the precedent period) and the effective (ex-post) rate of inflation } \\
& \mathrm{VEI}=\quad \text { Variation on the expected inflation rate } \\
& \mathrm{RP}=\quad \text { Risk premium, defined as the difference between the return of a "BAA" rated } \\
& \text { bond fund and a long-run government bond } \\
& \text { TSS }=\quad \text { Changes on term structure's slope, approximated by the difference between } \\
& \text { returns of bonds with different duration } \\
& \text { Market }=\quad \text { Market portfolio returns }
\end{aligned}
$$

and $r_{f t}$ is the risk-free rate that is approximate with the 3-month BOT returns. Table 1 reports basic statistics on the risk factors for the period June 1988 - June 1999. 
We approximate some of these factors as follows. Concerning the unexpected inflation rate, we calculate the difference between the expected inflation rate (the variation on M2-money aggregate) and the ex-post inflation rate (given by the rate of growth of the consumer price index (CPI)).

Once we have determined the expected inflation rate (as described above) its variation is easily calculated and the risk premium is determined by subtracting from a bond index return (JP Morgan Bond Italy) the ten-year BTP's yield ("Buoni Poliennali del Tesoro"). We capture the changes on the term-structure yield by making the difference between the ten-year BTP and the BOT and we approximate market index with the Comit Global index ${ }^{4}$.

As demonstrated by Grinblatt and Titman (1989), $\alpha$-Jensen's measure is not distorted if the fund manager is not a market timer. To consider the effect of timing ability, we apply the following two models developed in the literature: (i) Treynor and Mazuy (1966) and (ii) Merton (1981) and Henriksson and Merton (1981).

Treynor and Mazuy (1966) noted that, if fund managers possess timing ability, the portfolio characteristic line could not be straightforward. They captured the non-linearity of the Security Market Line, with the following model:

$$
r_{p t}-r_{f t}=\alpha_{p}+\beta_{p}\left(r_{M t}-r_{f t}\right)+\gamma_{p}\left(r_{M t}-r_{f t}\right)^{2}+\varepsilon_{p t}
$$

where $E\left(\varepsilon_{p t}\right)=0$, and $V\left(\varepsilon_{p t}\right)=\sigma^{2}$ and $\alpha, \beta$ and $\gamma$ are the regression's coefficients ${ }^{5}$. If the estimated $\gamma$ is significantly positive there is timing ability.

Merton (1981) and Henriksson and Merton (1981) developed an alternative approach.

Their model is:

$$
\begin{aligned}
& r_{M t}-r_{f t}=\alpha_{p}+\beta_{p}\left(r_{M t}-r_{f t}\right)+\gamma_{p i} \max \left[0,-\left(r_{M t}-r_{f t}\right)\right]+\varepsilon_{p t} \\
& \text { where } E\left(\varepsilon_{p t}\right)=0, V\left(\varepsilon_{p t}\right)=\sigma^{2}
\end{aligned}
$$

If the estimated $\gamma$ is significantly positive there is timing ability. It is interesting to note that Henriksson and Merton model the timing ability as a put option on market portfolio with strike price set to the risk-free rate. For this reason, the return deriving from timing ability, $\max \left[0,-\left(r_{M t}-r_{f t}\right)\right]$, is the option payoff. In particular, funds return is equal to the sum of the standard one factor model plus $\gamma_{p}$ put options on market portfolio. So, if market-timing activity can be interpreted as a put option, it is also possible to determine its theoretic value.

In addition, following Grinblatt and Titman (1994), we estimated total performance measures by adding the average return of market timing activity to the selectivity parameter $\alpha$ :

$$
\pi_{p}=\alpha_{p}+\gamma_{p i} \operatorname{Var}\left(r_{M t}-r_{f t}\right)
$$

In order to test the significance of total performance measures, the standard error has been calculated using the procedure suggested by Grinblatt and Titman (1994) ${ }^{6}$. 


\subsection{Empirical results}

We have estimated the Jensen's indicator and the timing coefficients performing also a series of tests to evaluate the fitting of the model and its stability during time. Even if the model describes quite well the phenomenon (the average $\overline{R^{2}}$ coefficient is 0.94 , with a minimum of 0.74 ) the parameters are rarely significant and only the Comit index ("market factor") is always different from zero at 99\% probability.

Considering residuals, both the tests on the AR(1) term and the Lagrange Multiplier test at one lag reject the presence of autocorrelation. Instead, the hypothesis of normality (Jarque-Bera's test) and homoschedasticity (White's test, ARCH(1) test and ARCH(4) test) cannot be accepted: $41 \%$ of the times the normality is rejected at a $95 \%$ level; $32 \%$ of the times the homoschedasticity is rejected at the same level of probability. The CUSUM test results confirm the stability of the model and the convergence of parameters. Table 2 shows the estimated results.

(Table 2: Mutual funds performances: $\alpha$-Jensen)

We see from Table 2 that, in most of the cases, fund managers are not able to generate extra-performances during the considered period. In fact, only six funds (which represent $10 \%$ of the sample) realised positive and significant (at 5\%) alphas.

These results seem to be equal to those of Cesari and Panetta $(1998,2002)^{7}$ and Otten and Bams (2002) because, in this study as in those papers, net returns are not significantly different from zero. It is interesting to observe that, even if we use different factor risks than Cesari and Panetta (2002) and Otten and Bams (2002) ${ }^{8}$, the results are still the same. This suggests that the robustness of these results is quite high.

In Table 3 we report market-timing coefficients. As for the $\alpha$-Jensen, timing coefficients are not statistically different from zero, denoting that managers cannot predict macro-movements on market. In addition, when we include a timing factor, the selectivity parameter ( $\alpha$-Jensen) is reduced by $0.17 \%$ per month and by $0.14 \%$ per month (on average), respectively, for the quadratic equation and for that of Henriksson and Merton. We see in Table 3 that only one fund shows the significant stock-picking ability. Finally, following Grinblatt and Titman's procedure, we estimated total performance measures. The results confirm the absence of superior abilities between fund managers: considering both existing models, the estimated $\pi$ are never significant.

(Table 3: Market Timing, Stock selection and Total performance)

Tables 2 and 3 demonstrate that a passive management ${ }^{9}$ of the benchmark produce the same performances than those realised by active fund managers, in line with some others studies produced on Italian market (see for example Cesari and Panetta (1998, 2002), Panetta and Zautzik (1991) and Ferretti and Murgia (1991)). Similar results were obtained by Grinblatt and Titman (1989) and Droms and Walker (1996). This leads us to conclude that the Italian capital market is efficient since institutional investors are unable to generate "extra returns" after taking into consideration transaction costs (excluded load fees). Nevertheless, this remains a crucial point for the analysis developed here: if the market is efficient, then investors are irrational when they buy active managed funds. On the other hand, if active managed funds realise superior performance, the market is 
not efficient. Cesari and Panetta (1998, 2002) and Otten and Bams (2002) assert that funds present extra-performances when gross returns are compounded, but, when net returns are considered, fund managers are unable to beat the market (in line with Grossman and Stiglitz (1980) and Cornell and Roll (1981) theories).

Other authors, such as Gruber (1996), formulate an alternative thesis, based on performance persistence. In the opinion of Gruber, the inability of a fund manager to beat the market does not necessarily imply his total lack of ability (he could be the "most skilled" of all the competitors). So, if abilities exist, fund returns would be foreseeable (at least in relative terms) and, if this is true, rational investors can realise superior performances by purchasing top performer funds and selling bottom performers. This is the crucial point of this work and we will dedicate to it the third section.

\section{PERFORMANCE PERSISTENCE ${ }^{10}$}

The question of whether equity fund performance is related to past performance has been discussed intensely in various studies, especially in the US. Grimblatt and Titman (1992), Hendricks, Patel and Zeckhauser (1993), Goetzmann and Ibbotson (1994), Brown and Goetzmann (1995), Malkiel (1995), Elton, Gruber and Blake (1996) and Gruber (1996) argue in favour of persistence in mutual fund returns. In particular, the previous studies generally find that persistence is concentrated mainly among the worst performers and that it tends to be strongest for short run periods. However, Cahart (1997) and Wermers (2000) suggest that this effect is mainly attributable to simple momentum strategies and Wermers (2001) finds that persistence is related to fund cash flows and portfolio turnover.

Although much has been clarified for the American market, little evidence has been brought up with regard the other markets. Exceptions are represented by Allen and Tan (1999), who study the persistence of UK investment trust companies and by Grunbichlrer and Pleschiutschnig (1999) and Otten and Bams (2002) concerning the European markets. The approaches followed to test performance persistence in previous studies are, in most of the cases, different and this is mainly related to the question investigated. In fact, a field of the literature analyses the patterns of persistent performance by applying the so called cross-sectional (non parametric) tests of performance persistence examining if there are any mutual funds that constantly beat competitors. The other field, called time series test of persistence, form portfolios of mutual funds according to prior performance and subsequently analyse the performance of these portfolios investigating if mutual funds with extra-return in this period will also have an above average return in the next period. The second approach has been used by Otten and Bams (2002); for this reason in our analysis we concentrate mainly on the former methodology.

Another issue related to the investigation of performance persistence is that it is not clear which is the right measure to use for mutual funds ability investigation. This phenomenon, in fact, could be studied using the indicators presented above or the total performance coefficients.

However, measures based on raw returns are imperfect. In fact, mutual fund performance cannot be evaluated without considering the level of risk. Unfortunately, if 
researchers agree on the necessity to associate a risk measure to returns, they do not agree on the most suitable risk indicator.

In our work we consider some risk-adjusted measures, which are most commonly used in the literature. We use Jensen's $\alpha$, with the relative market timing indicators, Sharpe's measure, Treynor's indicator and Sortino's indicator:

$$
\mathrm{S}_{\mathrm{p}}=\frac{\left(\bar{r}_{p}-\bar{r}_{f}\right)}{\sigma_{P}}, \quad \mathrm{~T}_{\mathrm{p}}=\frac{\left(\bar{r}_{p}-\overline{\boldsymbol{r}}_{f}\right)}{\beta_{P}}, \quad \mathrm{So}_{\mathrm{p}}=\frac{\overline{\boldsymbol{r}}_{P}-\overline{\boldsymbol{r}}_{f}}{D D_{p}}
$$

$$
\text { with } D D_{p}=\sqrt{\operatorname{VAR}\left[\min \left(0, \bar{r}_{p}-\bar{r}_{f}\right)\right]} \text {. }
$$

The risk free rate represents the comparison term, but it could be another variable such as the average or median of returns. Continuous return data are calculated from the month-end exit price of the fund.

Before performing the performance persistence analysis about all of them it is important to verify if various performance measures provide the same evaluation about funds. It is well known, in fact, that several performance measures present different characteristics (in terms of risk measure), however it is particularly interesting to see if they produce analogous rankings of funds.

Table 4 reports the correlation among performance measure and indicates, in general, a high correlation between regressions based indicators ( $\alpha$-Jensen, Treynor and Mazuy $(\pi$ T-M) and Henriksson and Merton $(\pi \mathrm{H}-\mathrm{M}))$ and, it also suggests a high correlation between the coefficients of Sharpe, Treynor and Sortino; nevertheless, it indicates little correlation between them and regression-based measures.

(Table 4: Correlation and rank correlation between various performance measures)

Table 4 also reports rank order correlations between different measures. These results seem to indicate a weak relation between rankings for any measures.

\subsection{The estimation method and statistical tests}

We evaluate the level of persistence on Italian equity funds in line with Gruber (1996) approach by adopting several criteria of analysis. First, we analyse persistence on raw and risk-adjusted returns (with the performance measures described above).

Second, we consider the effect of a temporal lag on the persistency level. While we investigate only short run persistence on raw returns (on four months and annual intervals), concerning risk-adjusted performance we examine also long-run persistence. More precisely, while we estimate the hot-hand phenomenon on four months and annual lags, long-run persistence has been evaluated on an interval of five and two years and a half. These periods have been determined in this way: in the first case we consider performances on two periods of the same length (of the entire sample period); in the second case we evaluate the phenomenon on the last five years of the sample with two intervals of the same length.

Finally, we analyse performance persistence with different statistical tests. "Cross product ratio" and independence $\chi^{2}$ have been divided on two macro-classes ("winners" and "losers"11); Spearman's rank order correlation and transition matrices have been 
applied on group (octiles) of funds; and cross-sectional regressions have been calculated for every single fund.

Total returns are determined on monthly or annual base and are continuously compounded. For risk-adjusted measures we have to discern between each single indicator. We estimate Jensen's indicator on the six factor Arbitrage Pricing Model (as described above) with regressions of 36-months ${ }^{12}$. While this window length does not produce any problem for long-run analysis, for the hot-hand phenomenon it causes evaluation windows overlapping. This effect could generate spurious persistence; for this reason we also estimate a model that overweighs the last observations. The same applies to total performance indicators. For Sharpe, Treynor and Sortino's measures the risk indicators have always been calculated on 36-months windows ${ }^{13}$ when we compute four months or annual returns. With this choice we produce consistent estimates that do not present the same problems encountered in Jensen's measure and in total performance coefficient estimations. In fact, the numerator of these ratios (the excess return) is calculated on non-overlapped intervals.

Regarding the statistical tests we use: Cross product ratio test and Chi-squared independence test. In particular, at each date (for example at the end of every quarter) we consider all the funds that are active at the end of the previous interval. ${ }^{14}$ Moreover, we compute the contingency Table of WW ("winner" in both periods), LL ("loser" in both periods), WL ("winner" in the first period, "loser" in the second) and LW ("loser" in the first period, "winner" in the second); and we calculate the cross-product ratio as follows:

$$
C P R=\frac{W W^{*} L L}{W L^{*} L W}
$$

This coefficient captures the fraction of funds that shows persistence: the null hypothesis of no-persistence corresponds to a CPR close to one. In other words, the null hypothesis corresponds to four classes of the same number of funds. We test this hypothesis using the statistic:

$$
Z=\frac{\ln (C P R)}{\sigma_{\ln (C P R)}} \quad \text { with } \quad \sigma_{\ln (C P R)}=\sqrt{\frac{1}{W W}+\frac{1}{L L}+\frac{1}{W L}+\frac{1}{L W}}
$$

that is normally distributed (see Christensen (1990)) .

Moreover, we implement a Chi-squared test to verify the independence of the distributions WW, WL, LL and LW. We perform this test at the end of the evaluation period and calculate the $\theta$ statistic as it follows:

$$
\theta=\frac{(W W-D 1)^{2}}{N}+\frac{(W L-D 2)^{2}}{N}+\frac{(L W-D 3)^{2}}{N}+\frac{(L L-D 4)^{2}}{N}
$$

where the frequencies $D 1=\frac{(W W+W L) *(W W+L W)}{N}, D 2=\frac{(W W+W L) *(W L+L L)}{N}$, $D 3=\frac{(L W+L L) *(W W+L W)}{N}$ and $D 4=\frac{(L W+L L) *(W L+L L)}{N}$.

The $\theta$ statistic, defined as Pearson's statistic, follows a $\chi^{2}$ distribution with one degree of freedom ${ }^{15}$. Finally, we examine these two tests modifying the "winner" definition: in this case a fund is inserted in that category if it exceeds the $75^{\text {th }}$ percentile return. 
We analyse the Spearman's rank order correlation and the transition matrices. At each date of the selection period (i.e. at every quarter, if we are evaluating persistence on four months returns) we sort the existing mutual funds with their realised performance. Then, we create eight portfolios of funds (the first is composed by top-performer funds returns equally weighted, the eighth of bottom performers ${ }^{16}$ ) and we evaluate the performances $^{17}$ in the subsequent period. Finally, we sort the portfolios and we verify, by performing Spearman's test ${ }^{18}$, if the ranking has been changed or not. The rank order correlation coefficient follows asymptotically a t-Student distribution with $\mathrm{N}-2$ degrees of freedom ${ }^{19}$, so it is possible to test the hypothesis of persistence (see Kendall et al. (1952)). In particular, we attest the absence of persistence by testing the null hypothesis of a Sperman's coefficient close to zero. This procedure is performed at each date, so we consider when funds remain in the same octile or when they change their position and toward which octile. In this way, we analyse the transition matrix on octiles between selection and evaluation periods.

Concerning Cross-sectional regressions, when we evaluate long-run persistence we use, as independent variable, the first lag of the dependent variable; while, when we evaluate the hot-hand phenomenon, we use, as independent variables, the lags 1-6 of the dependent variable (four months returns). This statistical technique takes into account the persistence by testing the return dependency between different periods. The null hypothesis of no persistence in this case corresponds to a regression coefficient statistically equal to zero. In synthesis, we examine performance persistence following the scheme (based on two-periods) presented in Figure 2.

(Figure 2: Experimental scheme of performance persistency's evaluation)

\subsection{Empirical results ${ }^{20}$}

The empirical results show the absence of the hot-hand effect on raw returns. In fact, even if the CPR exposed in Table 5 is significantly different from one, it refers only to the aggregate contingency Table: considering the results of this test at each date, we observe that the periods of persistence are lower than those of no-persistence. In addition, the $\theta$-test (which is powerful and also robust in presence of survivorship bias, as demonstrated by Carpenter and Lynch (1999)) confirms the absence of persistence.

\section{(Table 5: "Hot-hand phenomenon" on raw returns)}

Moreover, we employ the time series approach, as in the analysis of persistence performed by Otten and Bams (2002). In particular we form octile portfolios based on past mutual fund performance as already described above. We use formation period lengths of four and twelve months. The monthly returns on these portfolios are analysed using Jensen's $\alpha$ indicators and the market-timing indicator. The time-series test confirms the results of the cross-section test and those of Otten and Bams $(2002)^{21}$ : there is no evidence of performance persistence ${ }^{22}$.

If funds returns are influenced by a set of common factors, persistency could merely reflect differences in funds degree of risk. In this case one would expect riskier funds to show persistently higher returns than less risky funds. Therefore, we examine persistence of a series of risk-adjusted performance measures in the long run and in the short term. 
In order to analyse long-run persistence we perform cross-section studies using the six risk-adjusted returns measures presented above for ranking. Table 6 gives the results for persistence. In general, the risk-adjustment does not change dramatically the results obtained using raw returns; in fact, our results deny long-run persistence (on riskadjusted returns), whereas there is some evidence of a weak tendency to reversal.

(Table 6: Long-run persistence (on sample period length))

The reversal effect over long periods could be a reasonable matter for the Italian fund market. In fact, in a relative new market it appears rational that the fund disappearance is related to performances over long periods. Besides, some characteristics of the analysed market, such as the investors' insusceptibility to short periods of under-performance or the rigidity of supply structure, are justified by attrition costs that contrast the switching between funds ${ }^{23}$ in the Italian market.

Moreover, our analysis shows that performance persistence evaluation depends on the interval used. Considering the sample period length, empirical results indicate a weak tendency to reversal, whereas, taking into consideration the last five years of sample, fund ranking is independent between periods. In fact, if we are concerned about the values of CPR-test in Table 6 panel A (relative to the sample period length), it is always below one (which indicates reversal). Whereas, when we consider panel A of Table 7 (relative to the last five years of the sample), the CPR values are around one (see, for example, the values of CPR test for Sortino's indicator).

\section{(Table 7: Long-run persistence (last five years of sample))}

The relation between persistence and analysis period length is confirmed by the other tests. Considering panels-B of Table 6, we observe the larger presence of negative signs compared to Table 7 . In summary, empirical results suggest a low level of significance and the emerging point is the absence of long-run persistence on risk-adjusted returns.

In order to verify the hot-hand effect in the mutual funds market, we consider fourmonth risk-adjusted returns (with measures of Jensen and total performance) there is an overlapping on evaluation windows, which could generate spurious persistence.

We solve this problem and simultaneously estimate risk-adjusted measures on 36months lags, by using the "Discounted Least Squares" model (see Harvey (1990)) with a $\lambda$-value of 0.03 (on the basis of the empirical research on monthly financial series made by Zangari and Longerstaey (1996)).

For this reason, when we refer to DLS measures ( $\alpha$-Jensen and total performance indicators), we consider a measure in which both exogenous and dependent variables are weighted by $(1-\lambda)^{T-j}$ (where $T=35$ and $j=0, \ldots, 35$ ).

Our results suggest that persistence is related to the evaluation interval (yearly lags or four-month lags). In fact, while on yearly returns there is no persistence; on four-month returns we find evidence of persistence.

In particular, on yearly returns there is a weak uncertainty. Considering the results of $\chi^{2}$-test for Jensen's $\alpha$ and for Henriksson-Merton's total performance measure, we observe (Table 8, panel-A) that, at a confidence level of $92 \%$, we cannot reject the persistence hypothesis. However, when we introduce the correction for "windows overlapping", the same test does not reject the null hypothesis of no-persistence only at a 
confidence level of $85 \%$ (see panel A of Table 8 , DLS measures). This suggests that there is no evidence of persistence on yearly returns.

(Table 8: "Hot-hand phenomenon" on risk-adjusted measures)

On the contrary, we find evidence of persistence on four-month intervals. In fact, the larger part of these tests provides results in favour of persistence. All the statistical tests on Jensen's $\alpha$ and total performance (also after the correction) provide results in favour of persistence. On the other side, $\chi^{2}$-test on "winners" and "losers" refuse, at confidence level of $7 \%$, the null hypothesis of no-persistence for all the indicators (except for Sharpe's coefficient; see Table 8$)^{24}$.

Carpenter and Lynch (1999) demonstrated that $\theta$-test is robust and powerful in presence of survivorship bias (as in our sample, also considering the mentioned limitations). Moreover, according to Brown et al. (1992), when mutual fund survival is related to long-run persistence (as on Italian market), statistical tests could be influenced by spurious reversal effects. Given the above results, our analysis evidences the presence of persistence on four-month performances.

In addition, it is important to observe that we find the highest level of persistence when "winners" and "losers" are defined with respect to the median return. Moreover, Jensen's $\alpha$ and total performance coefficients maintain stable orders also considering octiles subdivision (not only subdivision in two macro-classes).

Maybe these results are affected by the approach we use to determine the Jensen's $\alpha$ and total performance coefficients for four months performance. However, persistence increases after the "overlapping correction", as a consequence our results are even more robust about this potential drawback.

Indeed, there are significant differences between the tests on Jensen's $\alpha$ and total performance coefficients and the tests on the other measures. The difference, which remains after the "overlapping correction", indicates a structural discordance on performance measures already evidenced by the correlation analysis presented in the previous section.

This is a crucial point: performance persistence results are related to the performance indicator. For this reason, it is important to analyse the phenomenon with several indicators to demonstrate if the persistence is robust.

\subsection{Multi-period tests of persistence}

In this section, following Agarwal and Naik (2000), we extend our investigation from the traditional two-periods framework to a multi-periods framework.

In this paper as in Agarwal and Naik (2000), we use Kolmogorov-Smirnov's test to implement a multi-period analysis of persistence. Kolmogorov-Smirnov's test evaluates the statistical differences between the empirical distribution of "winners" and "losers" 25 and the theoretical distribution in absence of persistence (binomial distribution).

We performed this test for all the performance measures considered and for four different windows. Table 9 provides an example of its results, where it is easy to observe that the maximum difference is 0.4 and so this test suggests refusing the null hypothesis of no persistence at $5 \%$ of significance.

(Table 9: Kolmogorov-Smirnov's test on four-year periods (Sortino's measure)) 
We performed the test with four different windows on six different performance measures. We see from Table 10 that for most of the windows the test suggests to reject the null hypothesis of no persistence for all the different measures considered. In particular, the windows that reject the null hypothesis for all the different performance measures are the four months and the three years windows.

However, the results of this test must be evaluated with particular attention, since some problem could arise from the low number of classes (only four classes for threeperiod-windows and five classes for four-period-windows). Kolmogorov-Smirnov's test refuses too easily the hypothesis of no-persistence when the number of classes is low. This effect derives from the limited number of classes, which causes also the weak power of the test. For this reason, rejections of persistence based only on KolmogorovSmirnov's test are not robust and this test has to be applied on time series of fund performance longer than that used in our sample.

(Table 10: Kolmogorov-Smirnov's test: Max absolute difference.)

\section{CONCLUDING REMARKS}

The performance of Italian managed funds has been little analysed. This current study aims to provide a comprehensive analysis of performance and performance persistence analysis of them. In particular in this work we evaluate the presence of "superior abilities" during the period March 1988 - August 1999. We investigate the presence of "talented mutual funds" in two ways. First, we measure their capacity to generate extrareturns (given the risk level); second, we investigate the presence of funds that are always the top performers and their capacity to generate extra-returns persistently during time. Concerning the last topic, we portray the relations between persistence and several variables such as: period length, performance indicator, performing class (e.g. octiles analysis or "winner" and "loser" analysis).

The study demonstrates that, in general, fund managers are not able to score extraperformances (in line with previous studies) and to remain top performers during considerable periods. More precisely, referring to the capacity to generate extra-returns over the sample, mutual fund managers do not possess significant "stock picking" or "market timing" abilities. Our results are coherent with those of the previous researches on the Italian fund market: in this work as in the studies of Ferretti and Murgia (1991), Cesari and Panetta $(1998,2002)$ or Otten and Bams (2002), there is no evidence of superior abilities after management fees and turnover costs had been deducted from returns.

Considering persistence analysis, we can summarise the results as follows. First, we cannot trace out the hot-hand phenomenon on raw returns. The no persistence effect is fairly robust to the methodology employed and persistence test. Second, there is no longrun persistence on risk-adjusted returns (we find a weak evidence of the reversal effect). Third, we find weak evidence of the hot-hand effect on risk-adjusted returns on fourmonth intervals. However, as soon as we analyse yearly intervals any evidence of persistence (which could be profitably exploited) disappears. 
This study offers an exhaustive analysis on performance persistence. In fact, in addition to study the relation between returns, we examine the effect of several variables (such as: stability class, performance measure, evaluation lag and statistical tests) on the levels of persistence. These factors, directly or indirectly, are always included in an analysis of performance persistence, but rarely (unique exception for the evaluation lag) previous studies evaluated their effect on the levels of persistence ${ }^{26}$. Instead, this study evidences the higher level of performance when: (i) we assume a temporal lag of fourmonths; (ii) we evaluate funds performance using Jensen's indicator; and (iii) we perform statistical tests on two macro-classes ("winners" and "losers" with respect to median return). This means that the results are quite sensitive to the measures of performance. 


\section{Footnotes}

${ }^{*}$ We would like to thank Alessandro Penati, Andrea Beltratti, Vikas Agarwal and participants of the 2001
EFMA Meeting in Lugano.
${ }^{1}$ Assogestioni (the Italian mutual funds association) classifies a mutual fund as "Azionario Italia" if the
net asset value (NAV) fraction invested on Italian stocks is at least $70 \%$.
${ }^{2}$ The importance of the benchmark specification in performance measurement is well documented.
Lehman and Modest (1987) and Grinblatt and Titman (1994) studied the effect of different benchmarks on
performance evaluation and show that the benchmark choice as well as the choice of the performance
measurement model has considerable impact on performance measure based rank ordering of mutual
funds. Elton, Gruber, Das and Hlavka (1993) show that the results of Ippolito (1989) are unreliable and
biased due to the miss-specification of the benchmark by neglecting the large proportion of small firms in
the portfolio of mutual funds.

${ }^{3}$ Factors 1-5 are derived from the study of Chen, Roll and Ross (1986).

${ }^{4}$ Even if we utilised this index, it is well known that value weighted Italian portfolios are not efficient (Ferretti and Murgia (1991) demonstrated that the Comit Global and also the Mib Storico indexes are inefficient).

${ }^{5}$ The formula refers to "the one factor model", but the model could be easily extended, as we do to a factor model (APT). In addition, it is important to remark that, in multiple regressions, timing ability may be evaluated for every risk factor; however, we evaluated it only for the market factor.

${ }^{6}$ Grinblatt and Titman developed a methodology to estimate the significance of total performance measure only for the Treynor and Mazuy approach. However, following Cesari and Panetta (1998) we applied it also to the Henriksson and Merton approach.

${ }^{7}$ Cesari and Panetta (2002) used (i) the single factor model (CAPM), (ii) a two index benchmark which includes both equity index and a value-weighted index of Italian government bonds, (iii) two benchmarks based on mimicking portfolio determined using factor analysis and (iv) the three-factor model proposed by Fama and French (1992).

${ }^{8}$ Otten and Bahms (2002) used the four-risk-factor model proposed by Cahart (1997) and Fama and Frech (1992) three-factor model.

${ }^{9}$ Following Gruber (1996), we use indifferently the expressions "market return" and "passive fund return" (also called "index fund"). In fact, the two expressions are not too different because "index funds" have the objective to replicate a benchmark portfolio (ex. MIB30, Mibtel, Standard and Poor's, etc.).

${ }^{10}$ In spite of its important implications, performance persistence is a phenomenon that has been studied only in the last decades (unique exception is Jensen (1968)). In fact, the principal contributes on subject are referred to Grinblatt and Titman (1992), Hendriks, Patel and Zeckhauser (1993), Goetzmann and Ibbotson (1994), Malkiel (1995), Brown and Goetzmann (1995), Carhart (1995), Elton et al. (1996), Brown, Goetzmann and Ibboltson (1996), Gruber (1996), Wermers (2000), Kent et al (1997) and Agarwal and Naik (2000).

${ }^{11}$ We defined a fund as "winner" if it excesses median return or, in another case, if it excesses the performance of the $75^{\text {th }}$ percentile.

${ }^{12}$ As mentioned above, in the first section, we considered this interval as the minimum length sufficient to have good estimations.

${ }^{13}$ When we considered these indicators to evaluate long-run persistence we estimated their risk measure considering the same lag (which is generally longer than 36 months) used to determine the excess return at the numerator.

${ }^{14} \mathrm{We}$ remark that, in our sample, funds do not become active at the same data.

${ }^{15}$ Although we evaluated the independence on the entire distribution of the sample, this $\chi^{2}$ test, like $\mathrm{CPR}$, could have been calculated at any date.

${ }^{16}$ The exact allocation procedure, following Hendriks et al. (1993), is as follows: let's assume $N_{t}$ the number of existing funds at that date and $\operatorname{rank}\left(r_{i}\right)$ the position of the i-th fund after ordering (in decreasing sense), then every fund will be assigned to the $\mathrm{j}$-th portfolio, which satisfies: 
$(j-1)\left\lfloor N_{t} / 8\right\rfloor+\sum_{k=1}^{j-1} \delta_{k} \leq \operatorname{rank}\left(r_{i}\right)<j\left\lfloor N_{t} / 8\right\rfloor+\sum_{k=1}^{j} \delta_{k}, \quad$ where: $\quad \delta_{k}=1 \quad$ if $k \leq\left(N_{t} \bmod 8\right) \quad$ and $\delta_{k}=0$ otherwise. ( $\lfloor$.$\rfloor indicates the integer part of the fraction).$

${ }^{17}$ The portfolio performance is the average performance of its funds.

${ }^{18}$ Spearman's ranking order correlation assumes values between -1 (the first ranking is the opposite of the second) and 1 (the two rankings are identical), through 0 (the two rankings are completely independent).

This coefficient captures rank order correlation and it is defined as: $r_{s}=1-\frac{6 \sum D_{i}^{2}}{N\left(N^{2}-1\right)}$, where D indicates ranking difference in the two dates and $\mathrm{N}$ indicates the number of components (in our case $\mathrm{N}=8$ ).

${ }^{19}$ Let's assume $r$ Spearman's coefficient, its test statistic will be: $t=r\left[(N-2) /\left(1-r^{2}\right)\right]^{\frac{1}{2}}$.

${ }^{20}$ Because of limited space, we present the most significant results of the research. In particular, we evidence the $\theta$ results since, as demonstrated by Carpenter and Lynch (1999), it is a powerful and robust test in presence of survivorship bias.

${ }^{21}$ See Table 9 in Otten and Bhams (2002).

${ }^{22}$ For brevity, we do not report the results. Results are provided upon request.

${ }^{23}$ In fact, banks are the principal suppliers of mutual fund's shares and every bank do not supply shares of all the existing mutual funds (on Italian market).

${ }^{24}$ We observed that Spearman's test refuses the null hypothesis 23 times on 23 for $\alpha-\mathrm{J}, 15$ times on 23 for $\pi^{\mathrm{H}-\mathrm{M}}, 11$ on 23 for $\pi^{\mathrm{T}-\mathrm{M}}, 1$ on 23 for Sharpe, 1 on 23 for Treynor and 2 on 23 for Sortino.

${ }^{25}$ We performed multi-period tests on "winners" and "losers" defined with respect to the median return.

${ }^{26}$ This is a relevant gap because, as we demonstrate, each one of these variables affects the level of persistence. 
Figure 1 - Fund's distribution for month of activity

Em pirical $D$ is tribution

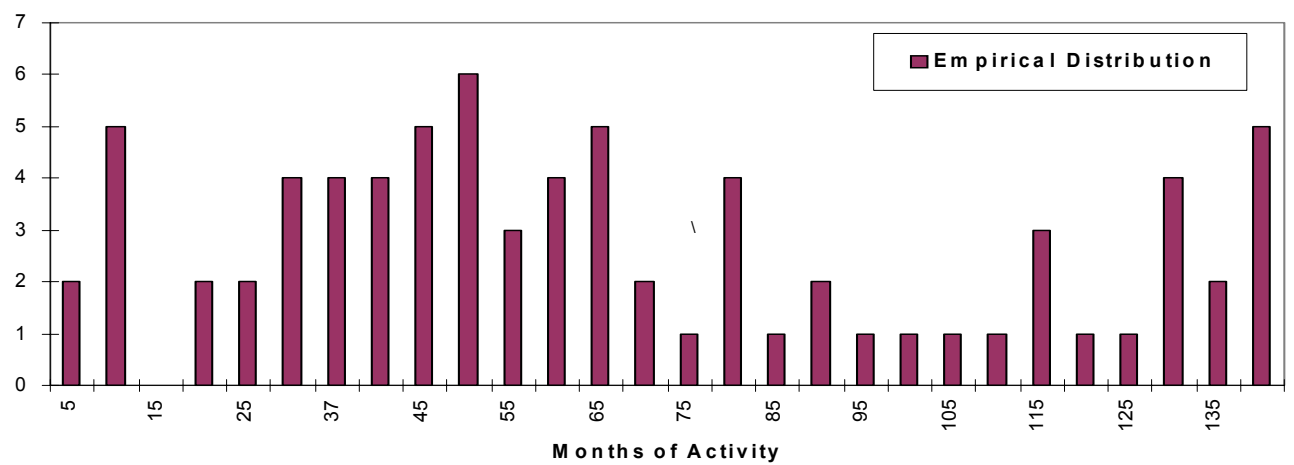

Figure 2 - Experimental scheme of performance persistency's evaluation

\begin{tabular}{|c|c|c|}
\hline Raw returns & $\begin{array}{l}\text { Short run persistence: } \\
>\text { quarterly returns; } \\
>\text { annual returns; }\end{array}$ & $\begin{array}{l}\text { Statistical tests: } \\
>\quad \text { CPR e } \chi^{2} \text { (on "winners" and "losers"); } \\
>\quad \text { Spearman' s coefficient and transition } \\
\text { matrices (on octiles); } \\
\text { cross-sectional regressions (on single } \\
\text { funds); }\end{array}$ \\
\hline \multirow{2}{*}{$\begin{array}{l}\text { Risk-adjusted } \\
\text { returns: } \\
>\quad \alpha-J ; \\
>\quad \alpha-J \mathrm{GLS} ; \\
>\quad \pi^{T-M} ; \\
>\quad \pi^{H-M} ; \\
>\quad \text { Sharpe; } \\
>\quad \text { Treynor; } \\
>\quad \text { Sortino; }\end{array}$} & $\begin{array}{l}\text { Short run persistence: } \\
\text { quarterly returns; } \\
>\quad \text { annual returns; }\end{array}$ & \multirow{2}{*}{$\begin{array}{l}\text { Statistical tests: } \\
>\quad \text { CPR e } \chi^{2} \text { (on "winners" and } \\
\text { "losers"); } \\
>\quad \text { Spearman' s coefficient and transition } \\
\text { matrices (on octiles); } \\
>\quad \text { cross-sectional regressions (on single }\end{array}$} \\
\hline & $\begin{array}{l}\text { Long-run persistence: } \\
>\quad \text { on two periods of } 5.5 \text { years; } \\
>\quad \text { on two periods of } 2.5 \text { years; }\end{array}$ & \\
\hline
\end{tabular}

Table 1 - Summary statistics for risk factors.

\begin{tabular}{lcccccccc}
\hline \multicolumn{7}{c}{ Excess } & Standard & Cross Correlations \\
\cline { 4 - 9 } & Return Deviation & IP & UI & VEI & RP & TSS Market \\
\hline Market $-0.04 \%$ & $6.73 \%$ & 1.00 & & & & & \\
IP & $0.74 \%$ & $4.17 \%$ & 0.06 & 1.00 & & & & \\
UI & $-0.82 \%$ & $1.41 \%$ & 0.01 & 0.13 & 1.00 & & & \\
VEI & $-0.85 \%$ & $2.07 \%$ & 0.02 & 0.01 & -0.67 & 1.00 & & \\
RP & $-0.82 \%$ & $0.52 \%$ & 0.15 & 0.05 & 0.25 & 0.15 & 1.00 & \\
TSS & $4.01 \%$ & $7.77 \%$ & -0.18 & 0.20 & 0.12 & -0.02 & 0.26 & 1.00
\end{tabular}

The Market factor is the portfolio returns of Comit Global Index. The excess return is calculated by subtracting the 3 month BOT interest rate. The IP factor is the monthly variations of industrial production The UI factor is constructed as the difference between the variation on M2-money aggregate and the rate of growth of the consumer price index (CPI). VEI is the variation on the expected inflation rate. The RP factor represents the risk premium, defined as the difference between the return of a "BAA" rated bond fund and a long-run government bond. TSS represents the changes on term structure slope, approximated by the difference between returns of bonds with different duration. 
Table 2 - Mutual funds performances: $\alpha$-Jensen at $1 \%$ and $5 \%$ significance

\begin{tabular}{r|ccl|}
\hline \multicolumn{3}{|c|}{ Number of funds (5\% signif. Level) } \\
\hline & $\alpha-J$ positive & $\alpha-J$ negative \\
\hline Significant & 6 & 0 \\
Non significant & 40 & 12 \\
\hline \multicolumn{3}{|c|}{ Number of funds (1\% signif. Level) } \\
\hline & $\alpha-J$ positive & $\alpha-J$ negative \\
\hline Significant & 3 & 0 \\
Non significant & 43 & 12
\end{tabular}

Table 3 - Market Timing, Stock selection and Total performance (at 5\% significance level)

\begin{tabular}{r|cc|cc|cc|}
\hline Number of Funds & \multicolumn{2}{|c|}{$\begin{array}{c}\text { "Market timing” } \\
\text { ability }\end{array}$} & \multicolumn{2}{c|}{$\begin{array}{c}\text { "Stock selection" } \\
\text { ability }\end{array}$} & \multicolumn{2}{c|}{$\begin{array}{c}\text { "Total performance" } \\
\text { indicator }\end{array}$} \\
\hline Quadratic Model (T-M) & $\gamma$ & $\gamma$ & $\alpha$ & $\alpha$ \\
positive & negative & $\begin{array}{c}\pi=\alpha+\gamma \\
\text { positive }\end{array}$ & $\begin{array}{c}\pi=\alpha+\gamma \\
\text { negative } \\
\text { positive }\end{array}$ & negative \\
\hline $\begin{array}{r}\text { Significant } \\
\text { Non significant }\end{array}$ & 33 & 0 & 1 & 0 & 0 & 1 \\
\hline $\begin{array}{c}\text { Henriksson-Merton's } \\
\text { Model (put) }\end{array}$ & 20 & 36 & 21 & 37 & 20 \\
\hline $\begin{array}{r}\text { Significant } \\
\text { Non significant }\end{array}$ & 2 & 0 & 1 & 0 & 0 & 0 \\
\hline
\end{tabular}

Table 4 - Correlation and rank correlation between various performance measures

\begin{tabular}{|c|c|c|c|c|c|c|}
\hline Correlation & $\pi$ T-M & $\pi \mathbf{H}-\mathbf{M}$ & $\begin{array}{c}\alpha- \\
\text { Jensen }\end{array}$ & Sharpe & Treynor & Sortino \\
\hline$\pi$ T-M & 1 & 0,940542 & 0,644155 & $-0,1353$ & $-0,1116$ & $-0,0919$ \\
\hline$\pi$ H-M & & 1 & 0,512132 & $-0,1041$ & $-0,0608$ & $-0,0314$ \\
\hline$\alpha$-Jensen & & & 1 & 0,292 & 0,31275 & 0,2743 \\
\hline Sharpe & & & & 1 & 0,95849 & 0,9492 \\
\hline Treynor & & & & & 1 & 0,9939 \\
\hline Sortino & & & & & & 1 \\
\hline $\begin{array}{c}\text { Rank } \\
\text { correlation }\end{array}$ & $\pi$ T-M & $\pi \mathbf{H}-\mathbf{M}$ & $\begin{array}{c}\alpha- \\
\text { Jensen }\end{array}$ & Sharpe & Treynor & Sortino \\
\hline$\pi$ T-M & 1 & 0,047511 & 0,120236 & 0,1186 & $-0,0501$ & $-0,1921$ \\
\hline$\pi \mathbf{H}-\mathbf{M}$ & & 1 & 0,041418 & $-0,2541$ & 0,15738 & $-0,0622$ \\
\hline$\alpha$-Jensen & & & 1 & 0,1434 & 0,05937 & 0,006 \\
\hline Sharpe & & & & 1 & 0,13171 & 0,0839 \\
\hline Treynor & & & & & 1 & 0,3641 \\
\hline Sortino & & & & & & 1 \\
\hline
\end{tabular}


Table 5 - "Hot-hand phenomenon" on raw returns

Panel A: "Winner" if it excess median return

\begin{tabular}{crrrrrrrrr}
\hline Lag & \multicolumn{1}{c}{$\mathbf{N}^{\circ}$} & \multicolumn{1}{c}{ WW } & \multicolumn{1}{c}{ LL } & \multicolumn{1}{c}{ LW } & \multicolumn{1}{c}{ WL } & CPR & Z-statistic & \multicolumn{1}{c}{$\theta$} & p-value \\
\hline 4 months & 1037 & 280,75 & 280,75 & 237,75 & 237,75 & 1,394 & $2,668 * *$ & 1,783 & 0,1818 \\
Year & 263 & 79,75 & 79,75 & 52,75 & 50,75 & 2,376 & $3,427 * *$ & 2,989 & 0,0838 \\
\hline
\end{tabular}

Panel B: "Winner" if it excess $75^{\text {th }}$ percentile

\begin{tabular}{crrrrrrrrr}
\hline Lag & $\mathbf{N}^{\circ}$ & WW & LL & LW & WL & CPR & Z-statistic & $\theta$ & p-value \\
\hline 4 months & 1037 & 84,06 & 611,56 & 170,69 & 170,69 & 1,765 & $3,574 * *$ & 2,215 & 0,1367 \\
Year & 263 & 25,62 & 163,12 & 37,63 & 36,63 & 3,033 & $3,526 * *$ & 2,329 & 0,1270 \\
\hline
\end{tabular}

$*$ indicates $5 \%$ significance, $* *$ indicates $1 \%$ significance.

"WW" indicates the number of persistence cases on "winners"; "LL" indicates the number of persistence cases on "losers"; "LW" and "WL" express the number of reversal cases (respectively from "loser" to "winner" and from "winner" to "loser"). "CPR" expresses the value of "Cross-Product Ratio"; "Z-statistic" indicates the value of statistic test on "CPR"; " $\theta$ " indicates the value of this test and "p-value" refers to $\chi 2$ test.

Table 6 - Long-run persistence (on sample period length)

Panel A $A^{1}$ : "Cross-product ratio" and

\begin{tabular}{crrrrrrrr}
\hline Measure & WW & LL & LW & WL & CPR & Z-statistic & $\chi^{2}$ & p-value \\
\hline$\alpha-J$ & 4 & 4 & 5 & 5 & 0,64 & $-0,47$ & 0,056 & 0,8129 \\
$\pi^{\mathrm{H}-\mathrm{M}}$ & 3 & 3 & 6 & 6 & 0,25 & $-1,386$ & 0,500 & 0,4795 \\
$\pi^{\mathrm{T}-\mathrm{M}}$ & 5 & 5 & 4 & 4 & 0,64 & 0,47 & 0,056 & 0,8129 \\
Sharpe & 4 & 4 & 5 & 5 & 0,64 & $-0,47$ & 0,056 & 0,8129 \\
Treynor & 4 & 4 & 5 & 5 & 0,64 & $-0,47$ & 0,056 & 0,8129 \\
Sortino & 3 & 3 & 6 & 6 & 0,25 & $-1,386$ & 0,5 & 0,4795 \\
\hline
\end{tabular}

Panel B: Spearman's test and cross-sectional regression

\begin{tabular}{cccccc}
\hline Measure & \multicolumn{2}{c}{ Spearman } & \multicolumn{2}{c}{ Cross-sectional coeff. } & $\mathbf{R}^{2}$ cross-sect. regr. \\
\hline$\alpha-\mathrm{J}$ & $-0,5$ & $(-1,3229)$ & $-0,106$ & $(-2,013)$ & 0,2021 \\
$\pi^{\mathrm{H}-\mathrm{M}}$ & $-0,524$ & $(-1,386)$ & $-0,096$ & $(-1,326)$ & 0,099 \\
$\pi^{\mathrm{T}-\mathrm{M}}$ & $-0,214$ & $(-0,567)$ & $-0,085$ & $(-1,108)$ & 0,071 \\
Sharpe & 0 & $(0)$ & 0,0014 & $(0,0225)$ & 0,00003 \\
Treynor & $-0,0476$ & $(-0,1256)$ & $-0,0199$ & $(-0,2503)$ & 0,0039 \\
Sortino & 0,0238 & $(0,0623)$ & $-0,0273$ & $(-0,2614)$ & 0,0042 \\
\hline
\end{tabular}

1 "Winners" e "Losers" are defined with respect to median return;

$*$ indicates $5 \%$ significance, $* *$ indicates $1 \%$ significance.

Cross-sectional regression has 16 degree of freedom.

"WW" indicates the number of persistence cases on "winners"; "LL" indicates the number of persistence cases on "losers"; "LW" and "WL" express the number of reversal cases (respectively from "loser" to "winner" and from "winner" to "loser"). "CPR" expresses the value of "Cross-Product Ratio"; "Z-statistic" indicates the value of statistic test on "CPR"; " $\chi 2$ " indicates the value of this test and "p-value" refers to $\chi 2$ test.

"Spearman" reports the value of the test on octiles subdivision (in brackets the value of t-Student); "Crosssectional coeff." expresses the regression coefficient (in brackets the value of t-Student). 
Table 7 - Long-run persistence (last five years of sample)

Panel A ${ }^{1}$ : "Cross-product ratio" e

\begin{tabular}{crrrrrrrr}
\hline Measure & WW & LL & LW & WL & CPR & Z-statistic & p-value \\
\hline$\alpha-J$ & 6 & 6 & 11 & 11 & 0,248 & $-1,883$ & 0,9317 & 0,337 \\
$\pi^{\mathrm{H}-\mathrm{M}}$ & 9 & 9 & 7,5 & 7,5 & 1,44 & 0,52151 & 0,068 & 0,794 \\
$\pi^{\mathrm{T}-\mathrm{M}}$ & 8,5 & 8,5 & 8 & 8 & 1,129 & 0,174 & 0,008 & 0,9287 \\
Sharpe & 8,5 & 8,5 & 8 & 8 & 1,129 & 0,174 & 0,008 & 0,9287 \\
Treynor & 8,5 & 8,5 & 8 & 8 & 1,129 & 0,174 & 0,008 & 0,9287 \\
Sortino & 8,25 & 8,25 & 8,25 & 8,25 & 1 & 0 & 0 & 1 \\
\hline
\end{tabular}

Panel B: Spearman's test and cross-sectional regression

\begin{tabular}{crrrrr}
\hline Measure & \multicolumn{2}{c}{ Spearman } & \multicolumn{2}{c}{$\begin{array}{c}\text { Cross-sectional } \\
\text { coeff.. }\end{array}$} & $\mathbf{R}^{2}$ cross-sect. regr. \\
\hline$\alpha-\mathrm{J}$ & $-0,214$ & $(-0,056)$ & $-0,038$ & $(-0,8118)$ & 0,0190 \\
$\pi^{\mathrm{H}-\mathrm{M}}$ & $-0,310$ & $(-0,819)$ & $-0,192$ & $(-2,879)$ & 0,196 \\
$\pi^{\mathrm{T}-\mathrm{M}}$ & $-0,381$ & $(-1,008)$ & $-0,215$ & $(-3,273)$ & 0,240 \\
Sharpe & 0,5238 & $(1,3858)$ & 0,129 & $(1,1585)$ & 0,0415 \\
Treynor & 0,0238 & $(0,0623)$ & 0,1523 & $(1,2531)$ & 0,0482 \\
Sortino & 0,0952 & $(0,252)$ & 0,1528 & $(0,6594)$ & 0,0138 \\
\hline
\end{tabular}

Table 8 - "Hot-hand phenomenon" on risk-adjusted measures ${ }^{1}$.

Panel A: Yearly interval

\begin{tabular}{ccccccccc}
\hline Measure & WW & LL & LW & WL & CPR & Z-statistic & $\theta$ & p-value \\
\hline$\alpha-\mathrm{J}$ & 50,25 & 50,25 & 28,75 & 28,75 & 3,055 & $3,377^{* *}$ & 2,926 & 0,0871 \\
$\alpha-\mathrm{J} D L S$ & 47,75 & 47,75 & 31,25 & 31,25 & 2,335 & $2,606 * *$ & 1,723 & 0,1893 \\
$\pi^{\mathrm{H}-\mathrm{M}}$ & 52 & 52 & 27 & 27 & 3,709 & $3,907 * *$ & 3,956 & $0,0467 *$ \\
$\pi^{\mathrm{H}-\mathrm{M}}$ DLS & 48,5 & 48,5 & 30,5 & 30,5 & 2,529 & $2,838^{* *}$ & 2,051 & 0,1521 \\
$\pi^{\mathrm{T}-\mathrm{M}}$ & 49,25 & 49,25 & 29,75 & 29,75 & 2,741 & $3,070 * *$ & 2,407 & 0,1279 \\
$\pi^{\mathrm{T}-\mathrm{M}}$ DLS & 44,25 & 44,25 & 34,75 & 34,75 & 1,621 & 1,508 & 0,571 & 0,4499 \\
Sharpe & 42,25 & 42,25 & 36,75 & 36,75 & 1,322 & 0,874 & 0,191 & 0,6620 \\
Treynor & 44,25 & 44,25 & 34,75 & 34,75 & 1,621 & 1,508 & 0,571 & 0,4498 \\
Sortino & 47 & 47 & 32 & 32 & 2,157 & $2,372 *$ & 1,424 & 0,2327 \\
\hline
\end{tabular}

Panel B: Four-month intervals

\begin{tabular}{crrrrrrrr}
\hline Measure & \multicolumn{1}{c}{ WW } & \multicolumn{1}{c}{ LL } & \multicolumn{1}{c}{ LW } & WL & CPR & Z-statistic & \multicolumn{1}{c}{$\boldsymbol{\theta}$} & p-value \\
\hline$\alpha-J$ & 222,75 & 222,75 & 67,75 & 67,75 & 10,81 & $12,132 * *$ & 41,351 & $0 * *$ \\
$\alpha-J$ DLS & 209,5 & 209,5 & 81 & 81 & 6,69 & $10,271 * *$ & 28,42 & $0 * *$ \\
$\pi^{\mathrm{H}-\mathrm{M}}$ & 230,75 & 230,75 & 59,75 & 59,75 & 14,914 & $13,164 * *$ & 50,329 & $0 * *$ \\
$\pi^{\mathrm{H}-\mathrm{M}}$ DLS & 206,25 & 206,25 & 84,25 & 84,25 & 5,993 & $9,792 * *$ & 25,618 & $0 * *$ \\
$\pi^{\mathrm{T}-\mathrm{M}}$ & 220,25 & 220,25 & 70,25 & 70,25 & 9,830 & $11,794 * *$ & 38,726 & $0 * *$ \\
$\pi^{\mathrm{T}-\mathrm{M}}$ DLS & 204,75 & 204,75 & 85,75 & 85,75 & 5,701 & $9,569 * *$ & 24,373 & $0 * *$ \\
Sharpe & 161,25 & 161,25 & 129,25 & 129,25 & 1,556 & $2,65 * *$ & 1,762 & 0,1843 \\
Treynor & 166,75 & 166,75 & 123,75 & 123,75 & 1,816 & $3,555 * *$ & 3,182 & 0,0744 \\
Sortino & 167 & 167 & 123,5 & 123,5 & 1,829 & $3,596 * *$ & 3,257 & 0,0711 \\
\hline
\end{tabular}

1 "Winners" and "Losers" are defined with respect to median return;

$*$ indicates $5 \%$ significance, $* *$ indicates $1 \%$ significance.

Cross-sectional regression has 16 degree of freedom. "WW" indicates the number of persistence cases on "winners"; "LL" indicates the number of persistence cases on "losers"; "LW" and "WL" express the number of reversal cases (respectively from "loser" to "winner" and from "winner" to "loser"). "CPR" expresses the value of "Cross-Product Ratio"; "Z-statistic" indicates the value of statistic test on "CPR"; " $\theta$ " indicates the value of this test and "p-value" refers to $\chi 2$ test. 
Table 9 - Kolmogorov-Smirnov's test on four-year periods (Sortino's measure)

\begin{tabular}{|c|c|c|c|}
\hline Interval & Empirical distrib. & Theoretical distrib. & Absolute diff. \\
\hline -inf. $<x<2.1875$ & 0 & 0 & 0 \\
\hline $2.1875<=\mathrm{x}<3$ & 0 & 0.4 & 0.4 \\
\hline $3<=x<4$ & 0.2 & 0.4 & 0.2 \\
\hline $4<=x<7$ & 0.4 & 0.4 & 0 \\
\hline $7<=\mathrm{x}<8$ & 0.6 & 0.4 & 0.2 \\
\hline $8<=x<8.75$ & 0.6 & 0.4 & 0.2 \\
\hline $8.75<=x<13$ & 0.8 & 0.8 & 0 \\
\hline $13<=x<13.125$ & 1 & 0.8 & 0.2 \\
\hline \multirow{2}{*}{$13.125<=\mathrm{x}<$ inf. } & 1 & 1 & 0 \\
\hline & & Max: & 0.4 \\
\hline
\end{tabular}

"Empirical distrib." is the "empirical distribution function" of Kolmogorov-Smirnov's test determined on observed frequencies; "Theoretical distrib." is the same distribution function determined on theoretical frequencies (binomial distribution).

If some absolute difference is lower than 0.4 value, we accepted the null hypothesis of no-persistence at $5 \%$ significance.

Table 10 - Kolmogorov-Smirnov's test: Max absolute difference.

\begin{tabular}{ccccccc}
\hline Interval & raw returns. & a-J. & Sharpe & Treynor & Sortino & a-J GLS \\
\hline four years & 0.2 & 0.2 & 0.4 & 0.4 & 0.4 & 0.4 \\
three years & 0.5 & 0.5 & 0.5 & 0.5 & 0.5 & 0.5 \\
$4 \begin{array}{c}\text { periods of four } \\
\text { months }\end{array}$ & 0.4 & 0.4 & 0.4 & 0.4 & 0.4 & 0.6 \\
$\begin{array}{c}3 \text { periods of four } \\
\text { months }\end{array}$ & 0.5 & 0.5 & 0.5 & 0.5 & 0.5 & 0.5 \\
\hline
\end{tabular}

If the absolute difference is lower than 0.4 value the null hypothesis of no-persistence at $5 \%$ significance is accepted.

\section{REFERENCES}

AGARWAL, V. and NAIK N. Y. (2000), "Multi-period Performance Persistence Analysis of Hedge Funds", forthcoming paper on: Journal of Financial and Quantitative Analysis.

ALLEN, D. and TAN M. (1999) "A test of the Persistence in the Performance of UK Managed Funds", Journal of Business Finance and Accounting, Vol. 26, No. 5, pp. 559-593.

BROWN, S. J. and GOETZMANN W. N. (1995), "Performance Persistence", Journal of Finance, Vol. 50, No. 2, pp. 679-98.

BROWN, S. J., GOETZMAN W. N., IBBOTSON R. G. and ROSS S. A. (1992), "Survivorship Bias in Performance Studies", Review of Financial Studies, Vol. 5, No. 4, pp. 553-580. 
BROWN, S. J., GOETZMANN W. N. and IBBOTSON R. G. (1996), "Offshore Hedge Funds: Survival \& Performance 1989-1995”, Journal of Business, No. 72, pp. 91-117.

CARHART, M. M. (1997), "On Persistence in Mutual Fund Performance”, Journal of Finance, Vol. 52, No.1, pp.57-82.

CARPENTER, J. N. and LYNCH A. W. (1999), "Survivorship Bias and Attrition Effects in Measures of Performance Persistence", Journal of financial economics, No. 54, pp. 337-374.

CESARI R. and PANETTA F. (2002), "The Performance of Italian Equità Funds", Journal of Banking and Finance, 26, 1, 99-126.

CESARI, R. and PANETTA F. (1998), "Style, Fees and Performances of Italian Equity Funds", Temi di discussione del servizio studi Banca d'Italia, No. 325.

CHEN, N., R. ROLL. and ROSS S. (1986), "Economic Forces and the Stock Market", Journal of Business, Vol. 59, pp. 383-404.

CHRISTENSEN, R. (1990), “Log-linear Models”, Springer-Verlag, New York.

CORNELL, B. and ROLL R. (1981), "Strategies for Pairwise Competitions in Markets and Organisations", Bell Journal of Economics, pp. 201-213.

DROMS, W. and WALKER D. (1996) "Mutual Fund Investment Performance. The Quarterly Review of Economics and Finance, Vol. 36, No. 3, pp. 347-363.

ELTON, E. J., GRUBER M. J. and BLAKE C. R. (1996), “The Persistence of Riskadjusted Mutual Fund Performance", Journal of Business, Vol.69, No.2, 133157.

ELTON, E.J., GRUBER M. J., DAS M. J. and HLAVKA M. (1993), US-based International Mutual Funds: a Performance Evaluation, Review of Financial Studies, 6 1-21.

FAMA, E. F. (1970), "Efficient Capital Markets: a Review of Theory and Empirical Work", Journal of Finance, Vol. 25, pp.383-417.

FAMA, E. F. (1991), "Efficient Capital Markets: II”, Journal of Finance, Vol. 64, No. 5, pp. 1575-1617.

FAMA, E. F. and FRENCH K. (1992), The Cross Section of Expected Stock Returns, Journal of Finance, 47, 427-465

FAMA, E. F. and FRENCH K. (1993), Common Risk Factors in the Returns on Stocks and Bonds, Journal of Financial Economics, 33, 3-56.

FERRETTI, R. and MURGIA M. (1991), "Fondi Comuni di Investimento", in A. Penati (ed.), Il rischio azionario e la borsa, Milano, EGEA.

GOETZMANN, W. N. and IBBOTSON R. G. (1994), "Do Winners repeat? Patterns in Mutual Fund Performance", Journal of portfolio management, Vol. 20 (spring), pp. 9-18.

GRINBLATT, M. and TITMAN S. (1989), "Mutual Fund Performance: An Analysis of Quarterly Portfolio Holdings", Journal of Business, Vol. 62, No. 3, pp. 393416.

GRINBLATT, M. and TITMAN S. (1992), "The Persistence of Mutual Funds", Journal of Finance, Vol. 47, pp. 1977-1984.

GRINBLATT, M. and TITMAN S. (1994), "A Study of Monthly Mutual Funds Returns and Performance Evaluation Techniques", Journal of Financial and Quantitative Analysis, Vol. 29, No. 3, pp. 419-444.

GROSSMAN, S. J. and J. STIGLITZ (1980), "The Impossibility of Informationally Efficient Markets", American Economic Review, pp. 393-408. 
GRUBER, M. J. (1996), "Another Puzzle: The Growth in Actively Managed Mutual Funds", Journal of Finance, Vol. 51, No. 3, pp. 783-810.

GRUNBICHLER A., and PLESCHIUTSCHNIG U. (1999) "Performance Persistence:Evidence for the European Mutual Funds Market", Working Paper University of St. Gallen.

HARVEY, A. C., (1990), "The Econometric Analysis of Time Series", $2^{\text {nd }}$ ed., New York, Philip Allen.

HENDRICKS, D., PATEL J. and ZECKHAUSER R. (1993), "Hot-hands in Mutual Funds: Short-Run Persistence of Performance", Journal of Finance, Vol. 48, pp.93-130.

HENRIKSSON, R. and MERTON R. (1981), "On Market Timing and Investment Performance II: Statistical Procedures for Evaluating Forecasting Skill”, Journal of Business, Vol. 54, No. 3, pp. 513-534.

IPPOLITO, R. A. (1989), "Efficiency with Costly Information: A Study of Mutual Fund Performance, 1965-1984", Quarterly Journal of Economics, Vol. 104, No. 1, pp. 1-24.

JENSEN, M. (1968), "The performance of mutual funds in the period 1945-1964", Journal of Finance, Vol. 23, No.1, pp. 389-416.

JENSEN, M. (1969), "Risk, the Pricing of Capital Assets, and the Evaluation of Investment Portfolios", Journal of business, Vol. 42, No. 1, pp. 167-247.

KENDALL, M. G. and STUART A. (1952), "The Advanced Theory of Statistics", London, C. Griffin, vol. I.

KENT, D., GRINBLATT M., TITMAN S. and WERMERS R. (1997), "Measuring Mutual Fund Performance with Characteristic-Based Benchmarks", Journal of Finance, Vol. 52, no. 3, pp. 1035-1058.

LEHMAN, B. N. and MODEST D. (1987), "Mutual Fund Performance Evaluation: a Comparison of Benchmarks and Benchmarks Comparison", Journal of Finance, Vol. 42, pp. 233-265.

MALKIEL, B. G. (1995), "Returns from Investing in Equity Funds", Journal of Finance, Vol. 50, pp.549-72.

MERTON, R. (1981), "On Market Timing and Investment Performance I: An Equilibrium Theory of Value and Market Forecasts", Journal of Business, Vol. 54, No. 3, pp. 363-406.

OTTEN, R. and BAMS D. (2002), "European mutual fund performance", European Financial Management, Vol. 8, No. 1.

PANETTA, F. and ZAUTZIK E. (1990), "Evoluzione e Performance dei Fondi Comuni Mobiliari Italiani”, Temi di Discussione del Servizio Studi della Banca d'Italia, No.142.

TREYNOR, J. L. and MAZUY K. (1966), "Can Mutual Funds Outguess the Market?" Harvard Business Review, Vol. 44, No. 4, pp.131-136.

WERMERS, R. (2000) "Mutual Fund Performance: An Empirical Decomposition into Stock-Picking Talent, Transaction Costs and Expenses", Journal of Finance, Vol. 54, pp. 581-622.

WERMERS, R. (2001), "Predicting Mutual Funds Returns", mimeo, University of Maryland.

ZANGARI, P. and LONGERSTAEY J. (1996), "RiskMetrics Technical Document", $4^{\text {th }}$ ed., New York: Morgan Guaranty Trust Company. 